\title{
THE MEDICOLEGAL ASPECTS OF BURN CASES ADMITTED TO ASSIUT UNIVERSITY HOSPITALS DURING YEARS OF 2015 AND 2016
}

\section{By}

Safaa M.George and Nora Z.Abdellah*

Forensic Medicine and Clinical Toxicology Department, Faculty of Medicine, Assiut University, Egypt*

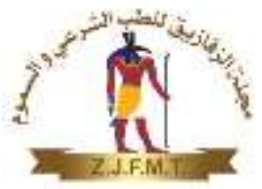

ABSTRACT

Background: Burns are not uncommon in Egypt, for successful prevention of such accidents it is essential to analyze the medicolegal aspects of these cases. The present study was conducted in Assiut university hospitals. Burn cases that were admitted to the emergency units during years of 2015 and 2016 were retrospectively analyzed from the available records.

Purpose: to investigate medicolegal aspects and demography of burn cases presented in emergency units at Assiut University Hospitals during years 2015 and 2016 to identify vulnerable personnel, and to evaluate their outcomes.

Methods: A retrospectives study analyzing data from the records between 01/01/2015 to 31/12/2016. Data regarding age, gender, type of burn, percentage of body surface area involved in burn, hospital stay of victims, fate of cases, and survival period of deceased victims was collected and analyzed using SPSS.

Results: The study revealed male predominance, 258 (75.26\%) male victims out of total 380 victims. The mean age for victims was 15.57 years with most of the victims $(52.89 \%)$ of burn were between the ages of 0 to 10 years, the minim age was 2 months while the maximum age was 73 years. Hot liquids and flame were the commonest causes of burn. $77.11 \%$ of burns in children age less than 11 years were due to hot liquids. The highest percentage of cases of burn was found in winter (29.2\%). 32.89\% of victims were students. The mean of hospital stay was 8.29 days. 17.63 $\%$ of burn victims admitted during these two years died.

Conclusions: Male victims represent most burn patients with children being more vulnerable. Preventive measures against burns should be taken in order to prevent burns particularly in children.

\section{INTRODUCTION}

Rurns are thermal injuries due to Bexposure to flame, hot liquids, electricity, radiation, or chemicals. ${ }^{1}$ Burn injuries are global health problem accounting for approximately 265000 deaths per year. ${ }^{2}$ Burns are major concern for governments, health authorities and forensic pathologists. ${ }^{3}$ The mean daily cost of burn dressings for burn patients in an Australian intensive care in 2007 was estimated to be $\$ 700 .{ }^{4}$ Most of burns occur in low and middle income countries. ${ }^{5}$ Throughout Africa the incidence of burns is increasing due to poverty, illiteracy, overcrowding, and due to the presence of establishment of slum areas with minimal safety measures. ${ }^{6}$

The effective approach to burn prevention must be based on a good knowledge of etiological patterns of burn injuries, the geographical variations and socioeconomic differences in epidemiology of burn. ${ }^{7}$

The most common causes of burns are fire and hot liquid. ${ }^{8}$ Despite being a preventable injury, scalds are a common injury in children and a frequent reason for hospitalization. ${ }^{9}$

Chemical burns represent a small proportion of cutaneous burn with an incidence of up to $10.7 \% .{ }^{10}$ Chemical 
burns caused by acids is not uncommon as an assault in developing countries. ${ }^{11}$

Electrical injury is the fourth most common cause of burn that continues to be one of the most distressing trauma injuries in developing countries. ${ }^{12}$

Burn injury has a wide spectrum of severity and outcome, ranging from superficial burns with no lasting physical disabilities or deformities to deep, large body surface area burns that profoundly affect life. Size and depth of burns are important factors affecting treatment and outcome. $^{13}$

\section{MATERIALS AND METHODS}

The present study was carried out retrospectively in burn unit in Assiut University hospitals, from the records between 01/01/2015 to 31/12/2016. Data regarding age, gender, type of burn, percentage of body surface area involved in burn, hospital stay of victims, fate of cases, and survival period of deceased victims was collected and analyzed using SPSS. Manner of burn was not included in data, as we could not distinguish between accidental and intentional burns because 'intent' is unlikely to be accurately ascertained from hospital records.

Inclusion criteria: All cases of burn presented in the emergency units at Assiut University Hospitals.

Ethical considerations: The Confidentiality of all records in this study were protected to the fullest extent possible .All ethical aspects related to research on records in Assiut University implicated in the study after the approval of the ethical committee.

Design: Observational retrospective descriptive study.

\section{RESULTS}

Table and figure one show the classification of burn cases according to sex. The total number of cases of burn presented in emergency units at Assiut University Hospital in year 2015 was (222 cases) distributed as (130 males and 92 females), while in year 2016 the total number of cases was (158 cases) distributed as (156 males and 2 females). There was a highly significant decrease in number of total cases in year 2016 (No 158 ) than the year 2015 (No 222) (p value $<0.01)$. There was an increase in the percentage of number of burned male victims (No 130) which represented (58.6\%) than females patients (No 92) which represented $(41.4 \%)$ in year 2015 while the majority of cases in 2016 were males (No 156) which represented $(98.7 \%)$.

The classification of the cases of burn presented in emergency units at Assiut University Hospital in relation to cause of burn in years 2015 \&2016 was shown in table (2) and figure (2). There were four main causes of burn involved in the studied cases in years 2015 and 2016; the highest percentage was caused by hot liquid followed by dry heat (flame), electricity then chemicals in year 2016. The total number of cases caused by hot liquid was 74 cases in year 2016 which represented $(49.4 \%)$ of total cases in this year (72 males and 2 females) while in year 2015 flame is the first cause. The total number of cases caused by flame was 107 cases which represented (48.2\%) of total cases in this year (67 males and 40 females). There was a highly significant difference in number of cases between male and female victims in different causes of burn in year 2016 (P. 
value $<0.01$ ) but there is no significant difference in year 2015 (P. value >0.05).

The age distribution of the burned cases presented in emergency units at Assiut University Hospital in years 2015 and 2016 was shown in table (3). The highest percentage of the cases of burn in years of 2015 and 2016 was found in age group 0 to 10 years, the total number was 127 cases, which represented $57.3 \%$ of the total cases in year 2015 and 74 cases, which represented $46.8 \%$ )of the total cases in year 2016.

Relation between causes of burns and different age group of the victims of burns at Assiut university Hospitals in years 2015 and 2016 was shown in table (4). The most common cause of burn in age group (0 to 10 years) was hot liquids (155 cases) followed by exposure to flame (43 cases).

Seasonal distribution of the victims of burns at Assiut university Hospitals in in years 2015 and 2016 was shown in table (5) and figure (3). The highest percentage of cases of burn was found in winter (61 cases in 2015 that represent $27.5 \%$ ) and (50 cases which represented $31.6 \%$ of in 2016). There was a highly significant increase in number of cases in winter season than other seasons in both years. In addition, there was a highly significant increase in number of cases in winter months in year 2016 than year 2015 (P. value <0.001).

Distribution of the victims of burns at Assiut university Hospitals in relation to their occupation in years 2015 and 2016 was shown in table (6) and figure (4): The highest percentage of cases was among student (75 cases), which represented (33.8. \%) and (50 cases) which represented $(31.6 \%)$ of total cases in years
2015 and 2016 respectively. There was a highly significant difference in number of cases between different occupations in years 2015 and 2016 (P. value $<0.01)$.

Fate of the victims of burns at Assiut University in years 2015 and 2016 was shown in table (7) and figure (5). The total number of cases ended in complete cure was 90 cases which represented (40.5\%) of total cases in year 2015 and 50 cases $(31.6 \%)$ in 2016 . There was a highly significant difference in number of cases in different fate patterns between years 2015 and 2016 (p. value<0.01). There was a highly significant increase in number of cases ended by escaping from hospital in year 2016 than year 2015 ( $\mathrm{p}$.value $<0.01$ ).

Deaths distribution of the victims of burns at Assiut university Hospitals in relation to age and sex in years 2015 and 2016 was shown in table (8). There was no significant difference in the percentage of deaths in male and female cases in different age groups in year 2015(p. value $>0.05$ ), while it's highly significant in 2016.

Death of the cases in relation to age and sex in year 2015 was distributed as following, the total number of deaths in age group 0-10 was (12 cases, which represented $28.5 \%$ ( 8 males and 4 female), followed by age group 11-20 years (9 cases), which represented $21.4 \%$ (7males and 2 females) then age group 21-30 years (7 cases), which represented $16.7 \%$ (4males and 3 females), then age group 41-50 years (5 cases), which represented $11.9 \%$ (1male and 4female), then age group 31-40 years ( 3 cases), which represented $7.1 \%$ (2males and 1 female). The number of deaths was equal in the another three groups (2 cases), which 
represented $4.8 \%$ of them (1male and 1 female) in all of them.

Deaths of the cases in relation to age and sex in year 2016 distributed as following, the total number of cases in age group 31-40 was (7 cases) which represented $28 \%$ (7 males), followed by age group 21-30 years (6 cases) which represented $24 \%$ (6 males), then age group 21-30 years (7 cases) which represented $16.7 \%$ (4males and 3 female), then age group 11-20 years ( 5 cases) which represented $20 \%$ (5 males cases), then age group 41-50 years (2 cases) which represented $8 \%$ ( 2 males cases), then age group 0-10 years (2 cases) which represented $8 \%$ (2males cases ), then the number of cases is equal in the another three groups (1 case) which represented $4 \%$ (1male) in all of them.

Distribution of burns over total body surface area of the victims of burns at Assiut university Hospitals in years 2015 and 2016 was shown in table (9). The current results showed that involvement of 11 to $20 \%$ of body surface in burn constituted $34.47 \%$ of cases (131), involvement of $0-10 \%$ constituted $23.86 \%$ of cases (90), involvement of $21-30 \%$ constituted $14.74 \%$ of cases (56), involvement of $31-40 \%$ constituted $8.68 \%$ of cases (33), involvement of $41-50 \%$ constituted $5.79 \%$ of cases (22), involvement of $71-80 \%$ constituted $3.16 \%$ of cases (12), involvement of $51-60 \%$ constituted $2.89 \%$ of cases (11), involvement of more than $90 \%$ constituted $2.64 \%$ of cases (10), involvement of $61-70 \%$ constituted $2.11 \%$ of cases (8), while involvement of 81$90 \%$ constituted $1.84 \%$ of cases (7). The highest percentage of total body surface area involved in burn was (11-20\%) which represent $(39.6 \%)$ in 2015 but in 2016 the most common surface area involved was (0-10\%), which represent (29.2\%) of cases.

Survival period of dead cases of burns at Assiut University Hospitals in years 2015 and 2016 was shown in table (10) and figure (6). The most common survival period was (1-3 days), which represent (31\%) in 2015 but in 2016 the most common period was in (5-7 days) ,which represent (32\%) of cases .

Relation between extent of burn and age group of the dead victims of burns at Assiut university Hospital in years 2015 and 2016 was shown in table (11). In 13 cases (19.4\%), total body surface area involved was above $80 \%$.

Distribution of burn degrees among the victims of burns at Assiut University Hospitals in years 2015 and 2016 was shown in table (12). 290 of all burn cases during the two years duration were third degree burn representing $79.28 \%$ of cases in 2015 and $72.15 \%$ of cases

2016. 
Table (1): Gender wise Distribution of cases of burns at Assiut University Hospitals in years 2015 and 2016.

\begin{tabular}{|l|l|l|}
\hline \multirow{2}{*}{ Males } & \multicolumn{2}{|c|}{ Number of cases } \\
\cline { 2 - 3 } & \multicolumn{1}{|c|}{2015} & \multicolumn{1}{c|}{2016} \\
\hline Females & $130(58.6 \%)$ & $156(98.7 \%)$ \\
\hline Total & $92(41.4 \%)$ & $2 \quad(3 \%)$ \\
\hline P. value & 222 & 158 \\
\hline
\end{tabular}

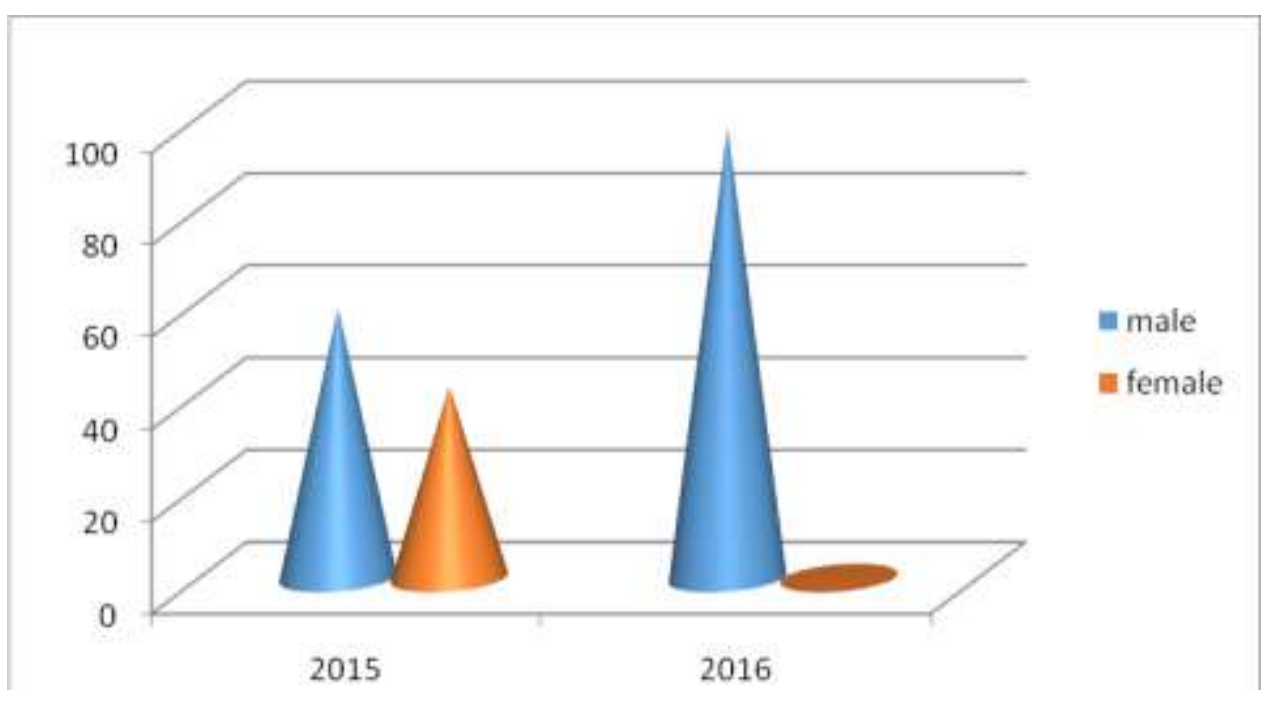

Fig (1); Gender wise Distribution of cases of burns at Assiut University Hospitals in years 2015 and 2016.

Table (2): Distribution of the victims of burns at Assiut University Hospitals in years 2015 and 2016 according to etiology of burn

\begin{tabular}{|c|c|c|c|c|c|}
\hline \multirow{3}{*}{ Etiology } & \\
\hline & \multicolumn{2}{|c|}{2015} & \multicolumn{2}{|c|}{2016} & \multirow[b]{2}{*}{ Total } \\
\hline & Male & female & Male & female & \\
\hline Flame & 67 & 40 & 66 & - & 173 \\
\hline Hot liquid & 56 & 47 & 72 & 2 & 177 \\
\hline Chemicals & 1 & - & 2 & - & 3 \\
\hline Electricity & 6 & 5 & 16 & - & 27 \\
\hline Total & 130 & 92 & 156 & 2 & 380 \\
\hline P. value & \multicolumn{2}{|c|}{0.116} & \multicolumn{2}{|c|}{$0.004 * *$} & \\
\hline
\end{tabular}




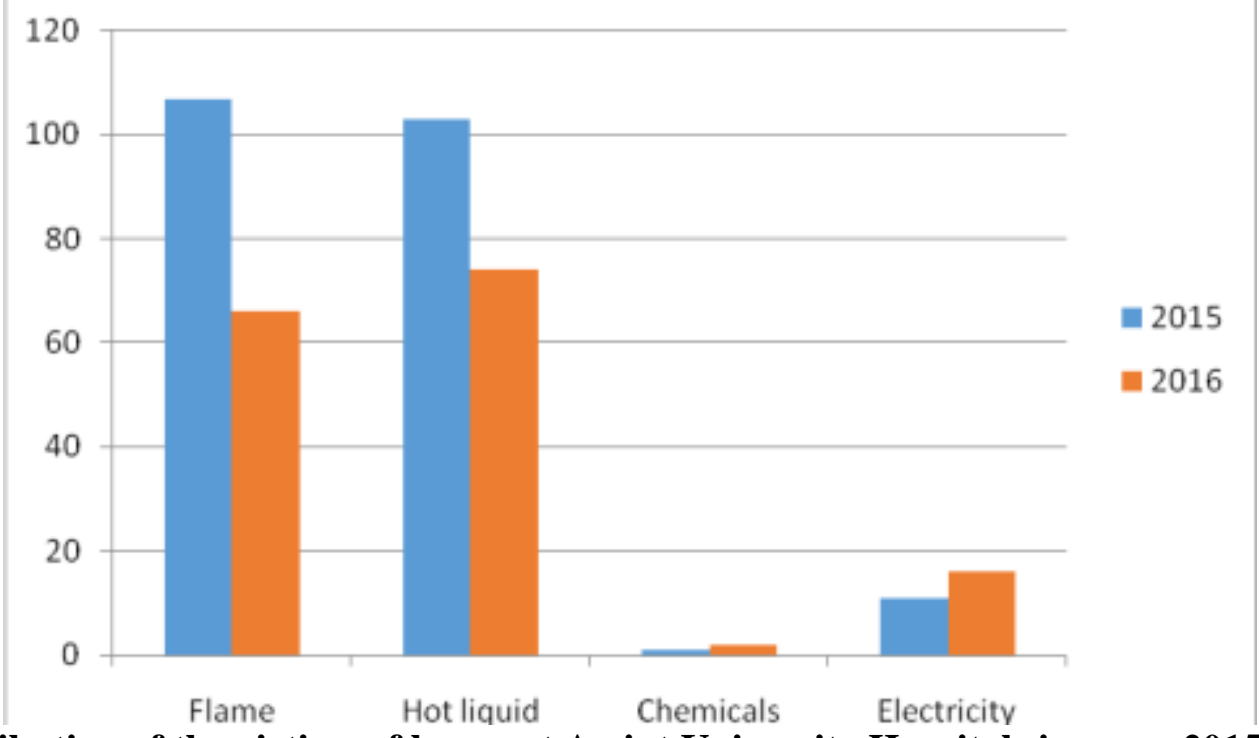

Fig. (2): Distribution of the victims of burns at Assiut University Hospitals in years 2015 and 2016 according to etiology of burn.

Table (3): Distribution of the victims of burns at Assiut University Hospitals in years 2015 and 2016 according to age groups.

\begin{tabular}{|c|c|c|}
\hline \multirow[t]{2}{*}{ Age group in years } & \multicolumn{2}{|c|}{ Number of cases } \\
\hline & 2015 & 2016 \\
\hline 0->10 & $127(57.3 \%)$ & $74(46.8 \%)$ \\
\hline $11->20$ & $34(15.3 \%)$ & $20(12.7 \%)$ \\
\hline $21->30$ & $19(8.5 \%)$ & $25(15.8 \%)$ \\
\hline $31->40$ & $16(7.2 \%)$ & $23(14.6 \%)$ \\
\hline $41->50$ & $14(6.3 \%)$ & $7(4 .+4 \%)$ \\
\hline $51->60$ & $5(2.3 \%)$ & $3(1.9 \%)$ \\
\hline $61->70$ & $4(1.8 \%)$ & $5(3.2 \%)$ \\
\hline $71->80$ & $3(1.3 \%)$ & $1(0.64)$ \\
\hline Total & $222(100 \%)$ & $158(100 \%)$ \\
\hline
\end{tabular}

Table (4): Relation between causes of burns and different age group of the victims of burns at Assiut University Hospitals in years 2015 and 2016.

\begin{tabular}{|c|c|c|c|c|c|c|c|c|c|}
\hline \multirow{2}{*}{ Age group } & \multicolumn{2}{|c|}{ Flame } & \multicolumn{2}{|c|}{ Hot liquid } & \multicolumn{2}{|c|}{ Chemicals } & \multicolumn{2}{|c|}{ Electricity } & \multirow{2}{*}{ Total } \\
\hline & 2015 & 2016 & 2015 & 2016 & 2015 & 2016 & 2015 & 2016 & \\
\hline $0->10 y$ & 37 & 6 & 90 & 65 & - & - & - & 3 & 201 \\
\hline $10->20 y$ & 30 & 12 & 2 & 2 & - & - & 2 & 6 & 54 \\
\hline $20->30 y$ & 15 & 13 & 4 & 10 & - & - & - & 2 & 44 \\
\hline $30->40 y$ & 10 & 18 & 4 & & - & - & 2 & 5 & 39 \\
\hline $40->50 y$ & 7 & 10 & & & - & - & 4 & & 21 \\
\hline $50->60 y$ & 6 & - & & & 1 & & 1 & - & 8 \\
\hline $60->70 y$ & 4 & 2 & & & 1 & & 1 & 1 & 9 \\
\hline $70->80 y$ & 2 & 1 & & & 1 & & & & 4 \\
\hline total & \multicolumn{2}{|c|}{173} & \multicolumn{2}{|c|}{177} & & 3 & \multicolumn{2}{|c|}{27} & 380 \\
\hline
\end{tabular}


Table (5): Seasonal distribution of the victims of burns at Assiut University Hospitals in in years 2015 and 2016.

\begin{tabular}{|c|c|c|c|c|}
\hline \multirow{2}{*}{$\begin{array}{l}\text { Seasonal } \\
\text { variation }\end{array}$} & \multicolumn{2}{|c|}{ Years } & \multirow[t]{2}{*}{ Total } & \multirow[t]{2}{*}{ P.value } \\
\hline & 2015 & 2016 & & \\
\hline Autumn & $56(25.2 \%)$ & $40(25.3 \%)$ & $96(25.3 \%)$ & 0.681 \\
\hline Winter & $61(27.5 \%)$ & $50(31.6 \%)$ & $111(29.2 \%)$ & $0.001 * *$ \\
\hline Spring & $53(23.9 \%)$ & $38(24.1 \%)$ & $91(24 \%)$ & 0.028* \\
\hline Summer & $52(23.4 \%)$ & $30(19 \%)$ & $82(21,5 \%)$ & 0.681 \\
\hline Total & 222 & 158 & 380 & --- \\
\hline
\end{tabular}

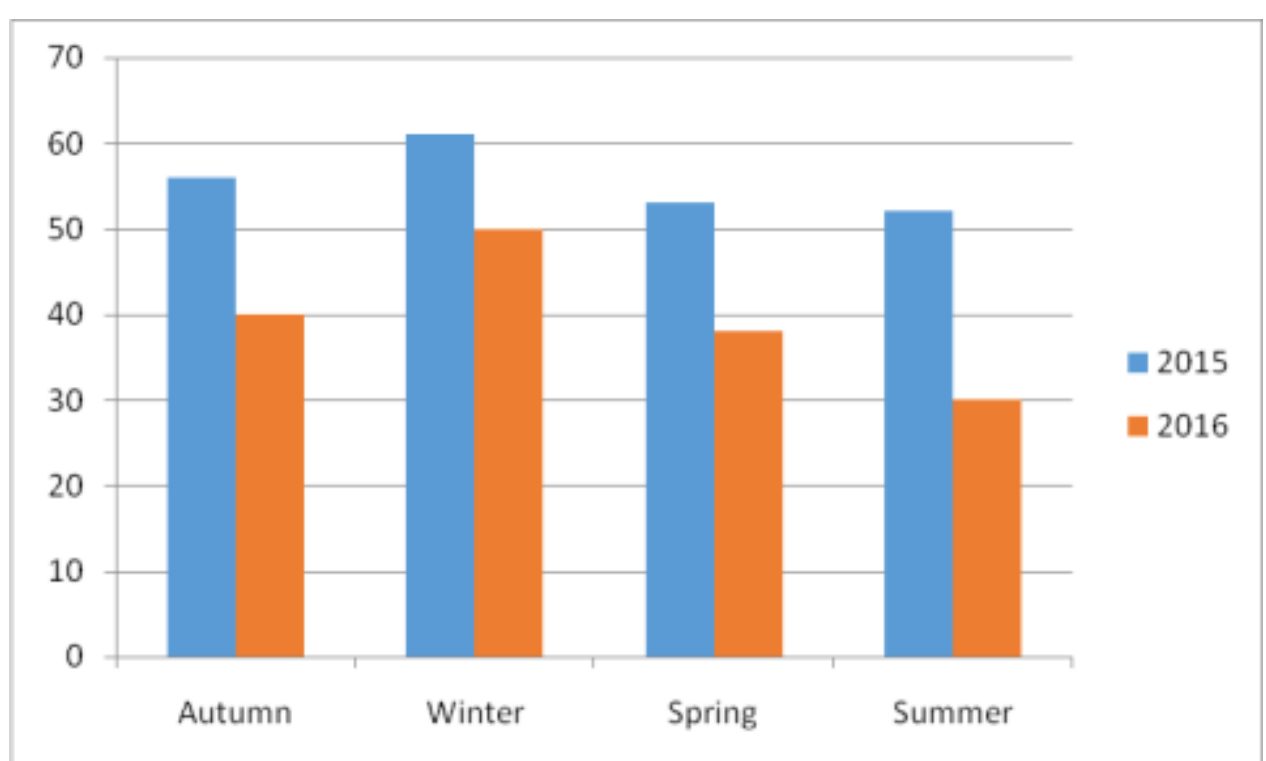

Fig (3): Seasonal distribution of the victims of burns at Assiut University Hospitals in years 2015 and 2016.

Table (6): Distribution of the victims of burns at Assiut University Hospitals in relation to their occupation in years 2015 and 2016.

\begin{tabular}{|c|c|c|}
\hline Occupation & $2015(n=222)$ & $2016(n=158)$ \\
\hline Preschool children & $50(22.5 \%)$ & $30(19 \%)$ \\
\hline Students & $75(33.8 \%)$ & $50(31.6 \%)$ \\
\hline Employees & $5(2.3 \%)$ & $8(5.1 \%)$ \\
\hline Farmers & $12(5.4 \%)$ & $20(12.7 \%)$ \\
\hline Factory Workers & $1(0.45 \%)$ & $3(1.9 \%)$ \\
\hline Military Soldiers & $2(0.90 \%)$ & $2(1.3 \%)$ \\
\hline Teachers & $5(2.3 \%)$ & $3(1.9 \%)$ \\
\hline Drivers & $4(0.18 \%)$ & $17(10.8 \%)$ \\
\hline Sellers & $6(0.27 \%)$ & $7(0.44 \%)$ \\
\hline Housewives & $40(18 \%)$ & $1(0.063 \%)$ \\
\hline Unemployed & $22(9.9 \%)$ & $17(10.8 \%)$ \\
\hline P. value & & \\
\hline
\end{tabular}




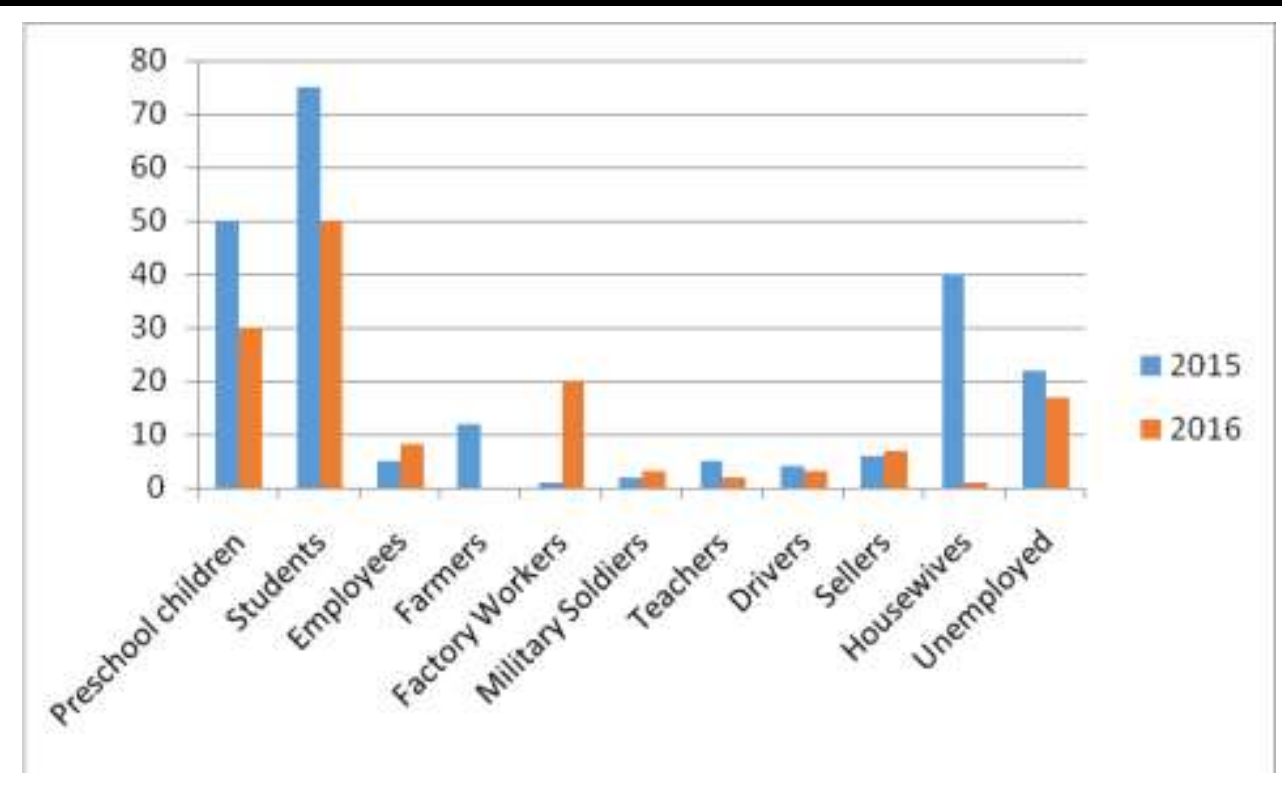

Fig:(4): Distribution of the victims of burns at Assiut University Hospitals in relation to their occupation in years 2015 and 2016.

Table (7): Fate of the victims of burns at Assiut University Hospitals in years 2015 and 2016

\begin{tabular}{|c|c|c|c|}
\hline Fate & $2015(n=222)$ & $2016(n=158)$ & P.value \\
\hline Complete cure & $90(40.5 \%)$ & $50(31.6 \%)$ & 0.516 \\
\hline Escape from hospital & $15(6.8 \%)$ & $20(12.6 \%)$ & $0.002 * *$ \\
\hline $\begin{array}{c}\text { Exit from hospital according } \\
\text { to patients request }\end{array}$ & $20(9.1 \%)$ & $10(6.3 \%)$ & $0.004 * *$ \\
\hline Hospital admission & $50(22.5 \%)$ & $40(25.3 \%)$ & $0.002 * *$ \\
\hline Death & $42(18.9 \%)$ & $25(15.8 \%)$ & 0.482 \\
\hline Transfer to other hospitals & $7(3.1 \%)$ & $13(8.3 \%)$ & 0.868 \\
\hline p. value & \multicolumn{3}{|c|}{$0.001 * *$} \\
\hline
\end{tabular}


90

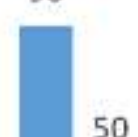

50

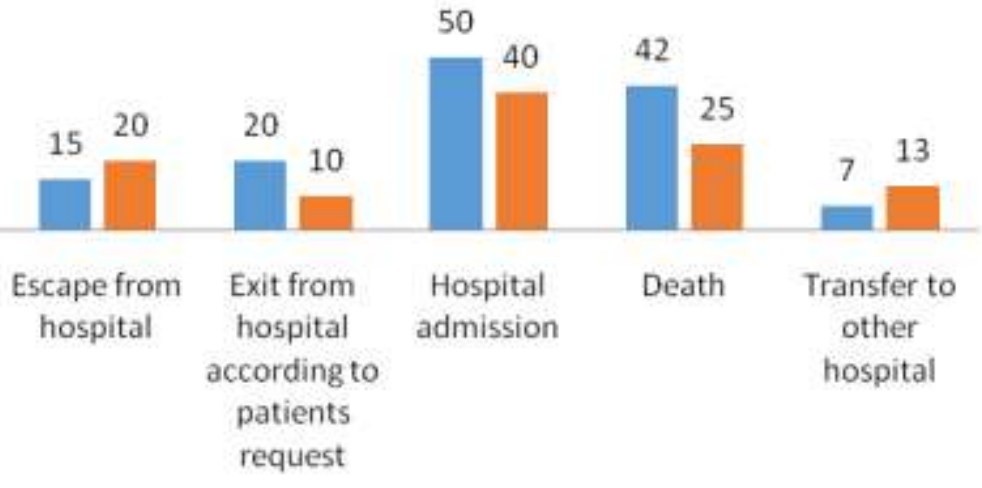

Fig (5): Fate of the victims of burns at Assiut University Hospitals in years 2015 and 2016

Table (8): Death distribution of the victims of burns at Assiut University Hospitals in relation to age and sex in years 2015 and 2016

\begin{tabular}{|c|c|c|c|c|c|c|}
\hline \multirow[t]{3}{*}{ Age group by years } & \multicolumn{6}{|c|}{ Years } \\
\hline & \multicolumn{3}{|c|}{2015} & \multicolumn{3}{|c|}{2016} \\
\hline & Males & Females & Total & Males & Females & Total \\
\hline 0-10 & 8 & 4 & $\begin{array}{l}12(28.5 \\
\%)\end{array}$ & 2 & - & $2(8 \%)$ \\
\hline $11-20$ & 2 & 7 & $9(21.4 \%)$ & 5 & - & $5(20 \%)$ \\
\hline 21-30 & 4 & 3 & $7(16.7 \%)$ & 6 & - & $6(24 \%)$ \\
\hline 31-40 & 2 & 1 & $3(7.1 \%)$ & 7 & - & $7(28 \%)$ \\
\hline 41-50 & 1 & 4 & $5(11.9 \%)$ & 3 & - & $3(12 \%)$ \\
\hline $51-60$ & $\mathbf{1}$ & 1 & $2(4.8 \%)$ & 1 & - & $1(4 \%)$ \\
\hline 61-70 & 1 & 1 & $2(4.8 \%)$ & 1 & - & $1(4 \%)$ \\
\hline $71-80$ & 1 & 1 & $2(4.8 \%)$ & - & - & - \\
\hline Total & 20 & 22 & 42 & 25 & - & 25 \\
\hline P.value & \multicolumn{3}{|c|}{0.184} & \multicolumn{3}{|c|}{$0.001 * *$} \\
\hline Mortality rate & \multicolumn{3}{|c|}{$18.9 \%$} & \multicolumn{3}{|c|}{$15.8 \%$} \\
\hline
\end{tabular}


Table (9): Distribution of burns over Total Body Surface Area of the victims of burns at Assiut University Hospitals in years 2015 and 2016

\begin{tabular}{|c|c|c|}
\hline \multirow{2}{*}{$\begin{array}{c}\text { Percentage of body surface } \\
\text { area involved in burn }\end{array}$} & \multicolumn{2}{|c|}{ Number of cases } \\
\cline { 2 - 3 } & \multicolumn{2}{|c|}{$\mathbf{2 0 1 5}$} \\
\hline $\mathbf{0 - 1 0 \%}$ & $44(19.8 \%)$ & $46(29.2 \%)$ \\
\hline $\mathbf{1 1 - 2 0 \%}$ & $88(39.6 \%)$ & $43(27.2 \%)$ \\
\hline $\mathbf{2 1 - 3 0 \%}$ & $34(15.3 \%)$ & $22(13.9 \%)$ \\
\hline $\mathbf{3 1 - 4 0 \%}$ & $18(8.1 \%)$ & $15(9.5 \%)$ \\
\hline $\mathbf{4 1 - 5 0 \%}$ & $16(7.2 \%)$ & $6(3.8 \%)$ \\
\hline $\mathbf{5 1 - 6 0 \%}$ & $7(3.2 \%)$ & $4(2.5 \%)$ \\
\hline $\mathbf{6 1 - 7 0 \%}$ & $5(2.2 \%)$ & $3(1.9 \%)$ \\
\hline $\mathbf{7 1 - 8 0 \%}$ & $3(1.4 \%)$ & $9(5.7 \%)$ \\
\hline $\mathbf{8 1 - 9 0 \%}$ & $4(1.8 \%)$ & $3(1.9 \%)$ \\
\hline $\mathbf{9 0}->\%$ & $3(1.4 \%)$ & $7(4.4 \%)$ \\
\hline Total & 222 & 158 \\
\hline
\end{tabular}

Table (10): Survival period of dead cases of burns at Assiut University Hospitals in years 2015 and 2016.

\begin{tabular}{|c|c|c|}
\hline & 2015 & 2016 \\
\hline Survival Period & \multicolumn{2}{|c|}{ Number } \\
\hline Less than 24 hours & $\mathbf{6 ( 1 4 . 3 \% )}$ & $\mathbf{5 ( 2 0 \% )}$ \\
\hline $1-3$ days & $13(31 \%)$ & $\mathbf{4}(16 \%)$ \\
\hline 3-5 days & $6(14.3 \%)$ & $\mathbf{2}(\mathbf{8 \%})$ \\
\hline 5-7 days & $\mathbf{1 0}(\mathbf{2 3 . 8 \%})$ & $\mathbf{8}(32 \%)$ \\
\hline Week- month & $\mathbf{7 ( 1 6 . 6 \% )}$ & $\mathbf{6}(\mathbf{2 4 \%})$ \\
\hline Total & $\mathbf{4 2}$ & $\mathbf{2 5}$ \\
\hline
\end{tabular}

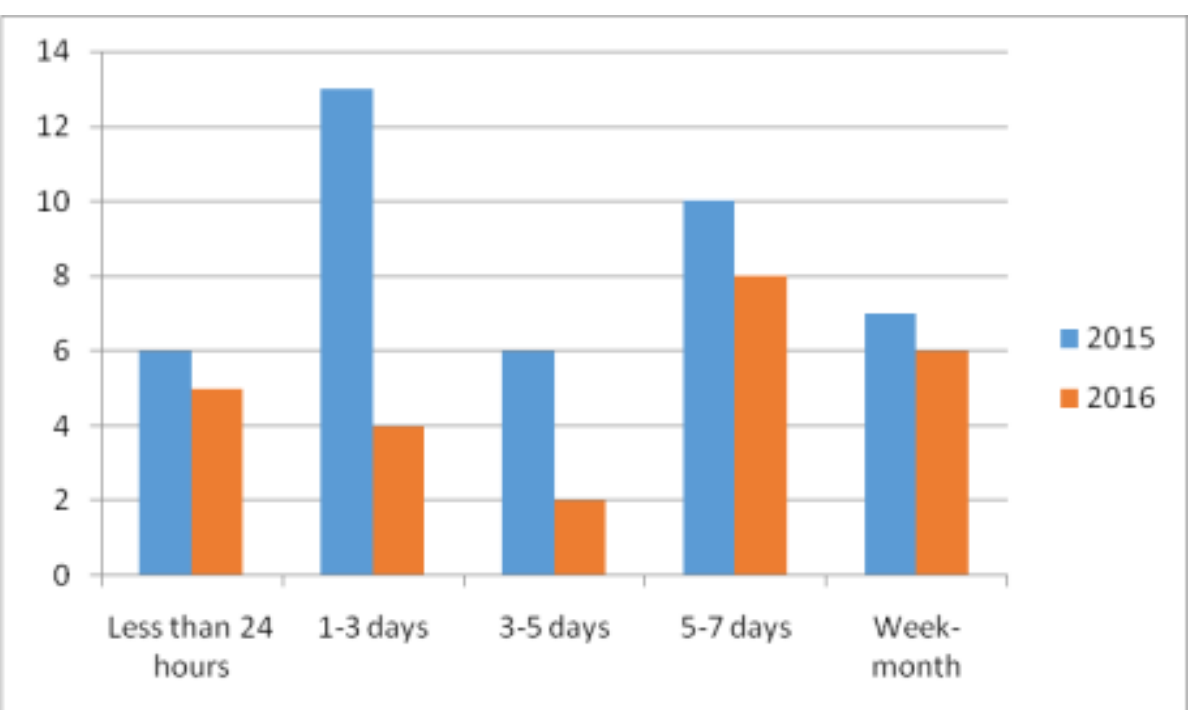

Fig. (6): Survival period of dead cases of burns at Assiut University Hospitals in years 2015 and 2016. 
Table (11): Relation between extent of burn and age group of the dead victims of burns at Assiut University Hospitals in years 2015 and 2016.

\begin{tabular}{|c|c|c|c|c|c|c|c|c|c|}
\hline $\begin{array}{l}\text { Age group } \\
\% \\
\text { of } \\
\text { burn }\end{array}$ & $0->10 y$ & $10->20 y$ & $20->30 y$ & $31->40 y$ & $41->50 y$ & $51->60 y$ & $61->70 y$ & 71->80y & Total \\
\hline $1-10 \%$ & - & $2(14.3 \%)$ & $1(7.7 \%)$ & $1(10 \%)$ & $1(12.5 \%)$ & $1(33.3 \%)$ & 1(33.3\%) & - & $7(10.4 \%)$ \\
\hline $11-20 \%$ & - & - & $4(20.8 \%)$ & $2(20 \%)$ & $4(50 \%$ & - & & - & $10(14.9 \%)$ \\
\hline $21-30 \%$ & - & $3(21.4 \%)$ & $2(10.4 \%)$ & $2(20 \%)$ & $1(12.5 \%)$ & $1(33.3 \%)$ & - & - & $9(13.5 \%)$ \\
\hline $31-40 \%$ & - & $2(14.3 \%)$ & $3(23 \%)$ & - & $2(25 \%)$ & - & - & - & $7(10.4 \%)$ \\
\hline $41-50 \%$ & - & $2(14.3 \%)$ & - & $2(20 \%)$ & - & - & - & - & $4(6 \%)$ \\
\hline $51-60 \%$ & $2(14.3 \%)$ & - & $3(23 \%)$ & $3(30 \%)$ & - & - & - & - & $8(12 \%)$ \\
\hline $61-70 \%$ & - & $3(21.4 \%)$ & - & - & - & - & - & - & $3(4.5 \%)$ \\
\hline $71-80 \%$ & $4(28.6 \%)$ & $2(14.3 \%)$ & - & - & - & - & - & - & $6(9 \%)$ \\
\hline $81-90 \%$ & - & - & - & - & - & $1(33.4 \%)$ & $2(66.6 \%)$ & - & $3(4.5 \%)$ \\
\hline$<90-\%$ & $8(80 \%)$ & - & - & - & - & - & - & $2(20 \%)$ & $10(14.9 \%)$ \\
\hline Total & 14 & 14 & 13 & 10 & 8 & 3 & 3 & 2 & $67(100 \%)$ \\
\hline
\end{tabular}

Table (12): Distribution of burn degrees among the victims of burns at Assiut University Hospitals in years 2015 and 2016

\begin{tabular}{|c|c|c|}
\hline \multirow{2}{*}{ Degree of burn } & \multicolumn{2}{|c|}{ Number of cases } \\
\cline { 2 - 3 } & \multicolumn{2}{|c|}{$\mathbf{2 0 1 6}$} \\
\cline { 2 - 3 } & \multicolumn{2}{|c|}{} \\
\hline First degree & $9(4.05 \%)$ & $6(3.8 \%)$ \\
\hline Second degree & $27(12.16 \%)$ & $30(18.99 \%)$ \\
\hline Third degree & $176(79.28 \%)$ & $114(72.15 \%)$ \\
\hline Fourth degree & $10(4.51 \%)$ & $8(5.06 \%)$ \\
\hline Total & 222 & 158 \\
\hline
\end{tabular}

\section{DISCUSSION}

Burn injury is a major cause of death, permanent infirmities and disfigurements. Burn injury has a very expensive treatment cost and prolonged hospital stay.

The current study is a retrospective study of cases of burn at Assiut University Hospitals during years 2015 and 2016 which showed that the total number of cases of burn presented in emergency unit at Assiut University Hospitals in year 2015 was 222 cases, while in year 2016 the total number of cases was 158 cases. The percentage of male victims was $58.6 \%$ of all victims admitted during year 2015 while the majority of cases in 2016 were males representing $98.7 \%$ of all victims. There was a highly significant difference in number of cases between male and female victims in different causes of burn in year 2016 ( $P$. value <0.01). This is in agreement with the work of Ahmad et al. who studied burns in patients presenting to a tertiary care hospital and concluded that $61.15 \%$ patients were males and $38.84 \%$ were females. $^{14}$

This is contrary to most studies in developing and low-income countries, which showed that females represent majority of burn victims. In a Pakistani study, out of the 114 burnt patients, majority (70 patients) were females $(61.4 \%)$ and males were $44(38.6 \%){ }^{15}$ Another recent Pakistani study showed that females represented $80.64 \%$ of suicidal burn victims. Many studies from developing countries reported that females commonly commits suicide by burn. ${ }^{16}$

The present study showed that out of 380 burns during the two years period; 177 were scalds due to hot liquids representing $46.6 \%$ of cases, 173 of cases were burns by 
flame representing $45.5 \%$. Only $7.1 \% \quad$ (27 victims) of burns cases were caused by electricity and 0.8 of cases (3) were chemical burns by acids. The present results are in agreements with the results of a Pakistani study, which demonstrated that scalds by hot liquids are more than other burns representing $41.2 \%$ of the total burn victims. ${ }^{15}$

Scalds account for one-third to one-half of all burns in high and middle-income countries and globally account for approximately $5 \%$ of all burn-related deaths. ${ }^{17,18}$ Scalds result from through spillage or immersion in hot water baths, hot foods and liquids, and hot cooking oils. ${ }^{19}$ Due to their thinner skin, children are more susceptible to the effects of scalds and develop more damage at a lower temperature than adults. ${ }^{20}$

The mean age of burn victims was 15.57 years. The most common age group in burned patients was (0-10 years) representing $57.3 \%$ (127 cases) of victims during 2015, and $46.8 \%$ (74 cases) of victims during 2016. The 2nd common age group was 11-20 years in 2015 representing 34 (15.3\%) and 21-30 years during 2016 representing $25(15.8 \%)$. The $3 \mathrm{~d}$ common age group was (21-30 years) $20(12.7 \%)$ in 2015 and (11-20 years) 19 (8.5\%) in 2016. The age group of 71-80 represented the least percentage of victims in 2015 and 2016 representing $3(1.3 \%)$ and 1 (o.64) respectively. Hot liquid was the cause of burn in children less than 11 year in $77.11 \%$ (155 out of 201 cases of the age group 1 to 10 years).

The current results demonstrate that the highest percentage of cases were student children (75 cases), which represent $33.8 . \%$ in 2015 and 50 cases which represent $31.6 \%$ of total cases in 2016. This contrary to the results of Kemp et al., which demonstrated that the age of one year is most common age for a child to suffer a burn with ten times as many burns and scalds as any school year age group. ${ }^{21}$

Burns represent the third cause of fatal injury in children after traffic accidents and drowning. ${ }^{22}$ In European hospitals, children are reported to account for almost half of all burns and scalds. ${ }^{23}$ Toddlers and children represent the most victims of burns, because of the general neurodevelopment, their curious nature and irresponsible behavior. ${ }^{24}$ Most caregivers usually have a tough time handling children during this stage of their developments. ${ }^{25}$ Infants are completely dependent on adults and burns during infancy is usually due to the negligence of the caregiver. Beside the economic burden, burns and scalds in children may result in physical disabilities and loss of school years. $^{26,27}$

The present results demonstrated that electrical burns affected only adult males due to occupational accidents. This is in agreement with a Chinese study, which showed that out of 595 electrical burn patients, $93.8 \%$ were males and $67.2 \%$ of victims were injured in workrelated circumstance. ${ }^{28}$

In much of the world, burns are more common in cold months. The seasonal variation of burn accidents may be attributed to the need for more hot water baths in winter. The traditional kerosene stove; which is still used in the poor areas for cooking and providing the necessary boiling water. This is concluded to be the cause of high number of flame and scald burns. ${ }^{29,30}$

The current study revealed that there was a highly significant increase in number of cases in winter season than other seasons. Our results showed that the highest percentage of the cases of burn in years of $2015(27.5 \%)$ and $2016(31.6 \%)$ was found in winter. In addition, there was a highly significant increase in number of cases in winter months in year 2016 than year 2015. This is in correlation with the results of Mostafa et al.who demonstrated that the highest proportion of burns in Cairo occurred in winter. ${ }^{29}$

According to percentage of burn surface area maximum number of patients in 2015 were $88 \&$ had $11-20 \%$ burn injuries on the other hand maximum number of patients in 2016 were $46 \&$ had $1-10 \%$ surface area with burn injuries. Only seven patients have shown $81-90 \%$ burns

The current data showed that $40.5 \%$ of cases ended in complete cure in year 2015 and 
$31.6 \%$ in 2016 . There was a highly significant increase in number of cases ended in escape from hospital in year 2016 than year 2015 ( $p$ .value $<0.01)$. There was no significant difference in the percentage of deaths in male and female cases in different age groups in year 2015(p. value $>0.05$ ), while it's highly significance in 2016. In year 2015, total deaths were 42 out of 222 cases representing $18.92 \%$ of cases with the highest percentage (12\%) in 010 year's age group. In year 2016, total deaths were 25 out of 158 cases representing $15.82 \%$ of cases with the highest percentage (7\%) in 3140 years age group. Studies regarding the relationship between age and mortality rate showed increase in mortality in children younger than 2 years old. ${ }^{31}$

The mortality rate in burned victims is determined by multiple factors including traditional factors as burn size and age of patients beside the occurrence of inhalation injury, shock and sepsis. ${ }^{8}$ There are important anatomical, physiological and psychosocial differences between adults and children. Children have different body proportions, thinner skin, smaller airways, and less blood volume. Thus are more vulnerable for complications, physical disabilities and death. ${ }^{13}$

No patients with total body surface area (TBSA) $\geq 90 \%$ burns survived in this study i.e100\% mortality. Recent U.S. data indicate a $69 \%$ mortality rate among patients with burns over $70 \%$ of TBSA. ${ }^{32}$ Even with advances in treatment of burn, the mortality rate remains high in severely burned cases. ${ }^{33}$

Our results regarding the survival period of dead cases of burns showed that the highest percentage of the survival period of dead cases was (1-3 days), which represent (31\%) in 2015 but in 2016 the most common period was in (57 days), which represent (32\%) of cases. The results of an Indian study concerning female burn victims showed that the survival period was $>3-7$ days in $44.3 \%$ cases. ${ }^{34}$ Another study showed that in $20.28 \%$ of victims included in the study the period of survival after sustaining burn injury was between 7 to 15 days followed by 3 to 7 days survival period in $18.84 \%$ of cases. ${ }^{35}$

Burn are classified into three degrees. The first-degree involve epidermis; the seconddegree burns involve epidermis and variable thickness of dermis, third-degree burn which involve the entire dermis and fourth degree: involve the entire skin and extend into fat, muscle, and bone. ${ }^{36}$

The current results showed that most burn victims suffered from third degree burns representing $79.28 \%$ and $72.15 \%$ in 2015 and 2016 respectively. While first-degree burns represented the least percentage; $4.05 \%$ and $3.8 \%$ in 2015 and 2016 respectively. This is in agreement with an epidemiological study of burns in Indonesia's national referral burn center from 2013 to 2015, which showed that the majority of both adults and children burn victims suffered from third-degree burn. ${ }^{37}$ Children with second degree of burn were the majority of burns in another study in Iraq. ${ }^{38}$ this can be understood as most first and superficial second-degree burns are treated in out patient's clinics. Many studies reported that seconddegree burns are the most common cases in outpatient clinics. ${ }^{39}$

\section{CONCLUSION AND RECOMMENDATIONS}

Burns are not uncommen in Assiut with children being the most vulnerable individuals. Males represent most burn patients. Burns most commonly occur due to exposure to hot liquids. Burn accident tend to occur more in winter season. Preventive measures against burns should be taken in order to prevent burns particularly in children and efforts should be done to increase literacy among the people especially the mother to provide safe home and kitchen appliance for preparing of food and heating.

\section{REFERENCES}

1. Modi N.J. (2009): 'Burns and Scalds', Modi's Medical Jurisprudence and Toxicology, , 23rd ed, LexisNexisButterworth's Wadhwa, Nagpur, p 629.

2. WHO, (2014): Whorl Health Organization. Burns, Available at: 
http://www.who.int/mediacentre/factsheets/f s365/en/. Accessed 5 June 2017.

3. Gonnade U and Farooqui JM (2013): Retrospective Analysis Of Death Due To Burns In Rural Region. Vol 22, Number 2 Journal of Forensic Medicine, Science and Law.

4. Patil V, Dulunty JM, Udy A, Thomas P, Kucharski G \& Lipman J.( 2010): Do burn patients cost more? The intensive care unit costs of burn patients compared with controls matched for length of stay and acuity. J Burn Care Res; 31(4):598-602.

5. Peck ,M and Pressman MA (2013):the correlation between burn mortality rates from fire and flame and economic status of countries. 39(6):1054-9. doi: 10.1016/j.burns.2013.04.010. Epub 2013 Jun 13.

6. Peck MD, Kruger GE, van der Merwe AE, Godakumbura W \& Ahuja RB. (2008): Burns and fires from non-electric domestic appliances in low and middle income countries Part I. The scope of the problem. Burns; 34:303-11.

7. Liao C.C., Rossignol A.M. (2000): Landmarks in burn prevention. Burns, 26 pp. 422-434 (August (5))

8. Macedo JL, and Santos JB (2007): Predictive factors of mortality in burn patients.Rev Inst Med Trop Sao Paulo. NovDec;49(6):365-70.

9. Riedlinger DI, Jennings PA, Edgar DW, Harvey JG, Cleland MH, Wood FM, Cameron PA. (2015) :Scald burns in children aged 14 and younger in Australia and New Zealand - an analysis based on the Burn Registry of Australia and New Zealand (BRANZ). Burns. May;41(3):462-8.

10. Hardwicke J, Hunter T, Staruch R, Moiemen N. (2013): Chemical burns--an historical comparison and review of the literature. Burns. May;38(3):383-7.

11. Das KK, Khondokar MS, Quamruzzaman M, et al. (2013); : Assault by burning in Dhaka, Bangladesh. Burns 39(1): 177-183.

12. Elloso M. S. and Cruz JJV. (2017): A review of electrical burns admitted in a Philippine Tertiary Hospital Burn Center. J Indian Acad Forensic Med. April-June Vol. 35, No. 2
13. Gill and Falder (2017): Early management of pediatrics burn injuries in pediatrics and child health 27(9); 406-414

14. Ahmad M, Yousaf A, Muslim M, Ahmad N, Maroof SA, Aurangzeb M. (2015): Epidemiology Of Burns In Patients Presenting To A Tertiary Care Hospital. J. Med. Sci. (Peshawar, Print) January, Vol. 23, No. 1: 30-33.

15. Makhdoom P A, Ansari R Z, Abbasi Ya, M, Ali $R$ A, Mengal FA (2015): Medicolegal Aspect of Burn Victims . P J M H S Vol. 9, NO. 1, JAN - MAR, 219-221.

16. Saaiq, M. (2016): Epidemiology and Outcome of Childhood Electrical Burn Injuries at Pakistan Institute of Medical Sciences Islamabad, Pakistan. J Burn Care Res March/April - 37 (2):174-180

17. Delgado J., Ramirez-Cardich M.E., Gilman R.H., Lavarello R., Dahodwala N., et al (2002): .Risk factors for burns in children: crowding, poverty, and poor maternal education. Inj Prev, 8 pp. 38-41

18. Peden M., K. Oyegbite, J. OzanneSmith, A. Hyder, C. Branche, et al. (2008): World report on child injury prevention. World health Organisation, Unicef

19. American Burn Association. National Burn Repository, (2009): www.ameriburn.org/NBRAnnualReport.pdf Version 5.0 (Accessed on June 12, 2017).

20. Cagle KM, Davis JW, Dominic W, Ebright S \& Gonzales W. (2006) :Developing a focused scald-prevention program. J Burn Care Res; 27:325-329.

21. Kemp A, Jones S, Lawson Z, Maguire SA.( 2014): Patterns of burns and scalds in children. Arch Dis Child. ;99:316-321.

22. Toon M.H., Maybauer D.M., Arceneaux L.L., Fraser J.F., Meyer W., Runge A., et al. (2011): Children with burns injuries assessment of trauma, neglect, violence and abuse. J Inj Violence Res, 3 (98-110 (July (2))

23. Brusselaers N, Monstrey S, Vogelaers D, Hoste E, Blot S (2010): ever burn injury in Europe: a systematic review of the incidence, etiology, morbidity, and mortality. Crit Care.; 14(5):R188.

24. Drago DA. (2005); Kitchen scalds and thermal burns in children five years and younger. Pediatrics 115:10-6. 
25. Agbenorku P (2013): Early childhood severe scalds in a developing country: A 3year retrospective study. mailto:pimagben@yahoo.comBurns_\& Trauma1:10030122

26. Sahu. S A, .Pankaj KA, and Patel K. (2016): Scald burn, a preventable injury: Analysis of 4306 patients from a major tertiary care center. Volume 42, Issue 8, December, 1844-1849

27. Gole H, Kimble R, Stockton K (2017): Bathroom scald burns in Queensland Children. Burns. May; 43(3):638-641.

28. Li H, Tan J, Zhou J, Yuan Z, Zhang J, Peng Y, Wu J, Luo G. (2017): Wound management and outcome of 595 electrical burns in a major burn center. J Surg Res. Jun 15;214:182-189.

29. Mostafa M. Afify, Naglaa F. Mahmoud, Ghada M. Forensic Abd El Azzim, Nevein A. El Desouky. (2012): Egyptian Journal of Sciences: Fatal burn injuries: A five years retrospective autopsy study in Cairo city, Egypt.; 2:117-122.

30. Tyson AF, Gallaher J, Mjuweni S, Cairns BA, Charles AG. (2017) : The effect of seasonality on burn incidence, severity and outcome in Central Malawi. Burns. Aug;43(5):1078-1082.

31. Wolf, S.E.; Rose, J.K.; Desai, M.H. et al. (1997): Mortality determinants in massive pediatric burns: an analysis of 103 children with $>$ or $=80 \%$ TBSA burns (> or $=70 \%$ full thickness). Ann. Surg., 225: 554-565,.

32. American Burn Association. National Burn Repository (2005): report. http://www.ameriburn.org/NBR2005. pdf

33. Pavoni V, Gianesello L, Paparella L, Buoninsegni LT, Barboni E (2010):
Outcome predictors and quality of life of severe burn patients admitted to intensive care unit. Scand J Trauma Resusc Emerg Med. Apr 27;18:24. doi: 10.1186/17577241-18-24.

34. Korah M K, Jyotish Guria2, Tulsi Mahto3, Ajay Bhengra (2016): Burn Deaths: A Study on Female Victims in Ranchi, Jharkhand. OSR Journal of Dental and Medical Sciences (IOSR-JDMS) eISSN: 2279-0853, p-ISSN: 22790861.Volume 15, Issue 11 Ver. VI PP 09-11

35. Chaudhary BL, Pradeep Yadav, Mukesh Kumar, Band Rahul (2013): Mortality Profile of Burn Injuries: A Postmortem Study in Lady Hardinge Medical College, New Delhi

36. Ethridge RT, Leong M, Phillips L. Wound healing. In: Touensend CM, Beauchamp RD, Evers BM, Mattox KL, (2009)L. Sabiston Textbook of surgery. $18^{\text {th }}$ ed. Philadephia: Saunders; pp. 191-216.

37. Wardhana A, Basuki A, Prameswara DH , Rizkita DN, Attika Andarie AA , Anissa Canintika AF (2017): The epidemiology of burns in Indonesia's national referral burn center from 2013 to 2015. Burns Open (2017), http://dx.doi.org/10.1016/j.burnso.2017.08.0 02

38. Rashid KJ, Babakir-Mina M, Abdilkarim DA (2017): Characteristics of Burn Injury and Factors in Relation to Infection among Pediatric Patients, MOJ Gerontology \& Geriatrics. 1 (3): 1- 11.

39. Taghavi M, Rasouli M.R, Boddouhi N et al. (2010): Epidemiology of outpatient burns in Tehran: An analysis of 4813 cases. Burns, 36: 109-13,. 


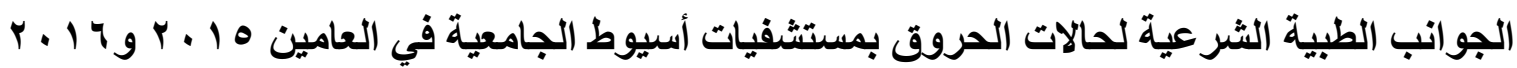

$$
\text { قسم الطب الشرعي و السموم الإكلينيكية ، كلية الطب جبدره ، جامعة أسيوط }
$$

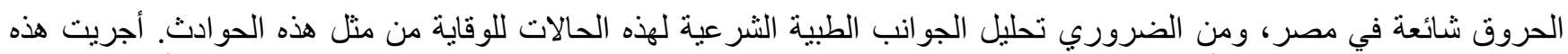

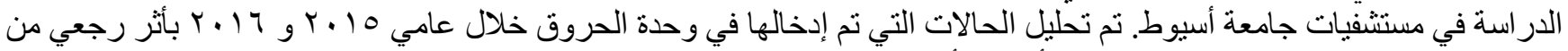

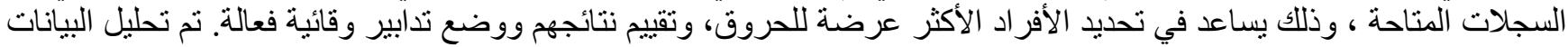

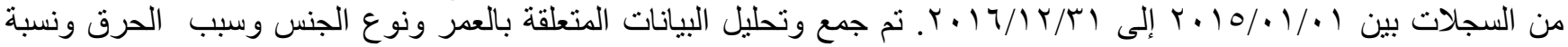

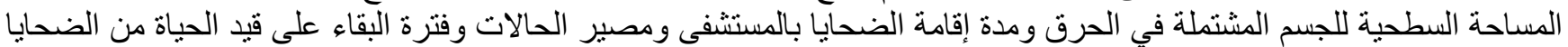

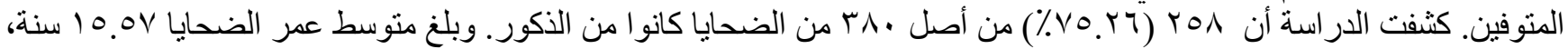

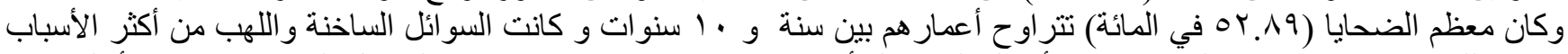

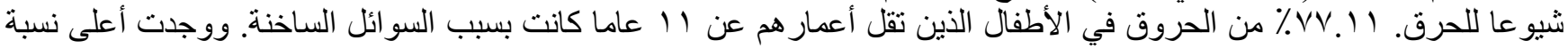

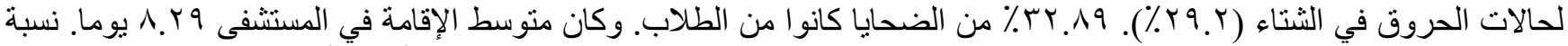

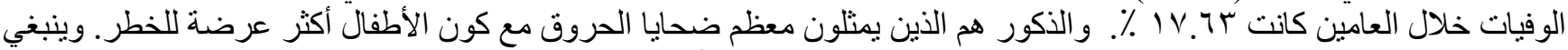
اتخاذ تدابير وقائية ضد الحين كانت الحروق للحيلولة دون حدوث حروق خاصنة عند الأطفال. 